\title{
Response of the Physiologic Gastroesophageal Sphincter to Increased Intra-abdominal Pressure *
}

\author{
Guido Van Derstappen $†$ and E. Clinton Texter, Jr. \\ (From the Northwestern University Medical School, Chicago, Ill.)
}

A zone of increased intraluminal pressure interposed between the tubular esophagus and presumed to be due to tonically contracted circular muscle fibers was described by Fyke, Code, and Schlegel (1) in 1956. Frequently only the narrow abdominal portion of this sphincter imposes a pressure barrier between the gastric and esophageal lumina when the pleuroperitoneal pressure gradient is increased (2-6). Reflux in patients with sliding hiatal hernia has been attributed to the upward displacement of the sphincter and the absence of the abdominal segment $(7,8)$.

Although there is agreement concerning the importance of the compression effect of increased intra-abdominal pressure during inspiration in the maintenance of sphincter competency, the role of the diaphragmatic crura remains controversial. Monges (9) showed that a balloon filled with radiopaque liquid in the esophagogastric area is compressed during deep inspiration in a ring-like fashion that he attributed to right crural contraction. Our studies were designed to contrast the effects of passive abdominal compression and deep inspiration on intraluminal pressure and $\mathrm{pH}$ and thereby to differentiate a crural (pinchcock) action from a dome (intra-abdominal pressure) action of the diaphragm.

\section{Methods and Materials}

Intraluminal pressures and $\mathrm{pH}$ were measured concurrently. Four water-filled, open-tip, polyethylene cath-

* Submitted for publication January 18, 1962 ; accepted March 12, 1964.

Supported in part by U. S. Public Health Service grants RG 4633-Physiol, A-2651, and 2A-5094, National Institute of Arthritis and Metabolic Diseases.

Abridgement of a thesis submitted by Dr. Van Derstappen to the faculty of the graduate school of Northwestern University in partial fulfillment of the requirements for the M. S. degree in medical science.

$\dagger$ Fulbright Traveling Fellow and trainee in gastroenterology, Northwestern University. Present address : 381 Antwerpsesteenweg, Lier, Antwerp, Belgium. eters (Clay-Adams PE 205 ; i.d., $1.55 \mathrm{~mm}$; length, 120 $\mathrm{cm}$ ) were used. The tips of the catheters were $5,1.5$, and $5 \mathrm{~cm}$ apart, permitting recording of pressures from the high pressure zone with the middle catheters and from the esophagus and stomach. The catheters were connected to external transducers (Statham P23Da) and an eight-channel carrier-amplifier and photokymograph (Sanborn 550M). Four channels were connected to a direct writing recorder for monitoring.

Intraluminal $\mathrm{pH}$ was measured by the method of Rovelstad, Owen, and Magath (10). The bulb of the glass electrode (Beckman no. 390 42) was located midway between the tips of the two proximal catheters. The catheters and electrode lead were tied with silk suture and enclosed in a Penrose drain. The electrode lead was connected to a $\mathrm{pH}$ meter (Beckman expanded scale no. 76). The circuit was completed by having the subject immerse an unabraded index finger in a saturated solution of potassium chloride containing a calomel electrode. The output of the $\mathrm{pH}$ meter was connected by a bridge circuit to the amplifier-recorder.

Respiratory movements were recorded by a crystal pneumograph connected to the recorder. The onset of deglutition was electrically recorded.

External abdominal compression was exerted by inflating a rubber balloon, 12 inches in diameter, which was connected to an aneroid manometer. The balloon was strapped around the subject's waist. The maximal intraballoon pressure varied between 90 and $120 \mathrm{~mm} \mathrm{Hg}$.

Forty-two normal subjects and 18 patients with a sliding hiatal hernia were studied. Simultaneous intraluminal pressures and $\mathrm{pH}$ measurements were performed during quiet respiration, deep inspiration, and external abdominal pressure on 20 normal young adults (ages, 22 to 27 years). To maintain intragastric $\mathrm{pH}$ between 1 and $2,300 \mathrm{ml}$ of $10 \mathrm{~N} \mathrm{HCl}$ was infused into the stomach at the beginning of the study.

In the remaining 20 individuals (ages, 35 to 74 years) intraluminal pressures were measured only during quiet respiration and deep inspiration. Intraluminal pressure measurements were repeated in 6 of this group after intravenous administration of $30 \mathrm{mg}$ of propantheline bromide. ${ }^{1}$

The catheters and $\mathrm{pH}$ electrode were inserted through the mouth and esophagus into the stomach, after which the subjects were placed in a supine position. Measurements were made at $0.5-$ to $1-\mathrm{cm}$ intervals as the

1 Supplied through the courtesy of G. D. Searle and Co., Chicago, Ill. 
catheters were withdrawn. Resting and deglutitive pressures and $\mathrm{pH}$ were recorded during quiet respiration, deep inspiration, and external abdominal pressure at each interval. Inspiration produced a positive deflection when the tip of the catheter was below the diaphragm and a negative deflection when the catheter tip was above the diaphragm. The point of respiratory reversal marked the diaphragmatic hiatus.

The peak height of the high pressure zone was expressed in millimeters of $\mathrm{Hg}$ exceeding fundic pressure and was obtained by subtracting fundic pressure from the maximal pressure in the high pressure zone. The intraluminal pressures during relaxation and the subsequent contraction of the gastroesophageal sphincter were expressed in millimeters of $\mathrm{Hg}$ greater or less than fundic pressure. It was impossible to effect identical increases in fundic pressure by external abdominal compression or by deep inspiration in each individual or in the same individual when measurements were made from different levels. The ratios between the amplitudes of the simultaneous pressure increases in the high pressure zone and in the fundus were calculated in order to compare the results. Standard statistical methods were employed.

\section{Results}

1) The characteristics of the high pressure zone in normal young adults

Intraluminal pressures from the gastroesophageal junction were measured 40 times in the 20 normal young adults. A zone where intraluminal pressures exceeded fundic pressure at the end of expiration was present in all subjects in 38 of the 40 observations. The high pressure zone was detectable only below the diaphragm on 2 occasions and only above the diaphragm on 3 occasions (Table I). The zone extended from $2.5 \mathrm{~cm}$ (range, 0.5 to 3.0 ) below the hiatus to $1 \mathrm{~cm}$ (range, 0.5 to 2.5 ) above the hiatus. The maxi-

TABLE I

Incidence of the sub- and supradiaphragmatic segment of the high pressure zone during 40 measurements in 20 normal young adults

\begin{tabular}{|c|c|c|c|}
\hline & $\begin{array}{c}\text { Entire } \\
\text { high } \\
\text { pressure } \\
\text { zone }\end{array}$ & $\begin{array}{c}\text { Subdia- } \\
\text { phrag- } \\
\text { matic } \\
\text { segment }\end{array}$ & $\begin{array}{c}\text { Supradia- } \\
\text { phrag- } \\
\text { matic } \\
\text { segment }\end{array}$ \\
\hline & $\%$ & $\%$ & $\%$ \\
\hline \multicolumn{4}{|c|}{ Before external abdominal pressure } \\
\hline $\begin{array}{l}\text { a) End-expiration } \\
\text { b) End-inspiration }\end{array}$ & $\begin{array}{l}95 \\
95\end{array}$ & $\begin{array}{r}92 \\
100\end{array}$ & $\begin{array}{l}95 \\
19\end{array}$ \\
\hline \multicolumn{4}{|c|}{ During external abdominal pressure } \\
\hline $\begin{array}{l}\text { a) End-expiration } \\
\text { b) End-inspiration }\end{array}$ & $\begin{array}{l}80 \\
89\end{array}$ & $\begin{array}{l}86 \\
97\end{array}$ & $\begin{array}{r}64 \\
8\end{array}$ \\
\hline
\end{tabular}

TABLE II

Mean maximal pressure of the high pressure zone

\begin{tabular}{|c|c|c|c|c|}
\hline & \multicolumn{2}{|c|}{ End-expiration } & \multicolumn{2}{|c|}{ End-inspiration } \\
\hline & Mean & $\mathrm{SE}$ & Mean & $\mathrm{SE}$ \\
\hline & \multicolumn{2}{|c|}{$m m \mathrm{Hg}$} & \multicolumn{2}{|c|}{$m m \mathrm{Hg}$} \\
\hline $\begin{array}{l}\text { Before external } \\
\text { abdominal pressure }\end{array}$ & 6.0 & 0.9 & 4.0 & 0.7 \\
\hline $\begin{array}{l}\text { During external } \\
\text { abdominal pressure }\end{array}$ & 4.8 & 0.9 & 3.9 & 0.6 \\
\hline
\end{tabular}

mal pressure of the high pressure zone was within $1 \mathrm{~cm}$ of the hiatus at end-expiration, being above the hiatus in $90 \%$ and below the hiatus in $10 \%$. The mean maximal pressure at end-expiration was $6 \mathrm{~mm} \mathrm{Hg}$ (range, 1 to 17) (Table II).

A high pressure zone at the end of inspiration was detected during $95 \%$ of the observations (Table I). The zone was always below the diaphragm, extending a mean length of $2.5 \mathrm{~cm}$ (range, 0.5 to 3.5 ). A high pressure zone above the diaphragm with a mean length of $0.75 \mathrm{~cm}$ (range, 0 to 1 ) was detected during $19 \%$ of the observations. Intraluminal pressures characteristic of the tubular esophagus were detected $3 \mathrm{~cm}$ (range, 0 to 3.5 ) above the hiatus. The maximal pressure of the high pressure zone was always below the hiatus; the mean maximal pressure was $4 \mathrm{~mm} \mathrm{Hg}$ (range, 1 to 12 ).

\section{2) Response of the physiologic sphincter to in- creased intra-abdominal pressure produced by external abdominal compression}

Intraluminal pressures from the gastroesophageal junction were measured 40 times in the 20 normal young adults. The pressures were recorded at $1-\mathrm{cm}$ intervals while external abdominal pressure was applied for a 30- to 60-second period. The mean rise in fundic pressure was $12 \mathrm{~mm} \mathrm{Hg}$ (range, 5 to 22 ). The diaphragmatic hiatus, as reflected by the point of respiratory pressure wave reversal, was measured at the same distance from the incisor teeth in $71 \%$ of the studies; in the remainder the location of the hiatus was within $1 \mathrm{~cm}$ of its location during quiet respiration.

During the application of external abdominal compression, the incidence of the supradiaphragmatic segment decreased significantly and was only present within $0.5 \mathrm{~cm}$ of the hiatus (Table I). The peak was always below the diaphragm at 


\section{END-EXPIRATION}

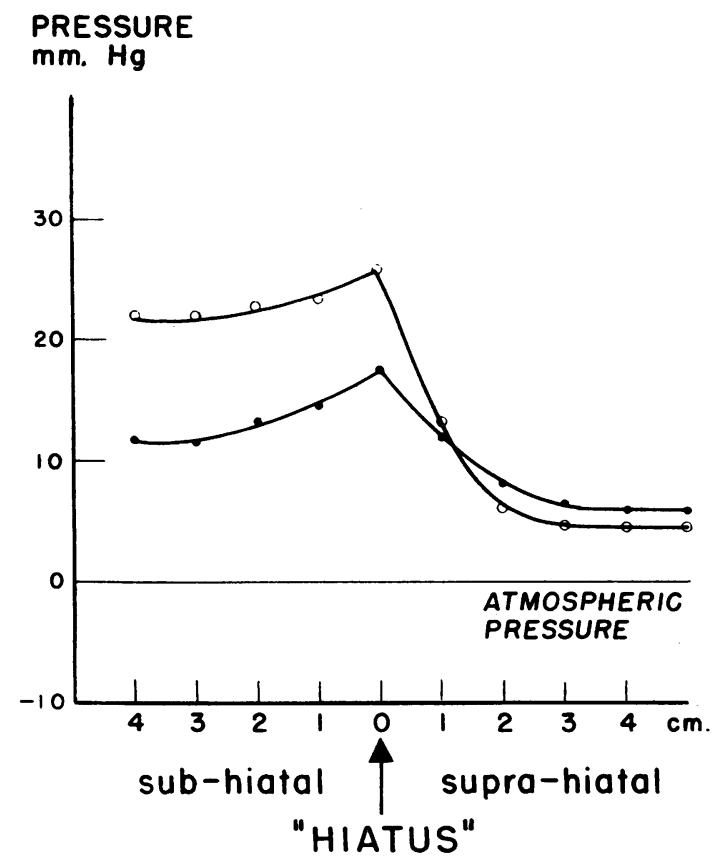

\section{END-INSPIRATION}

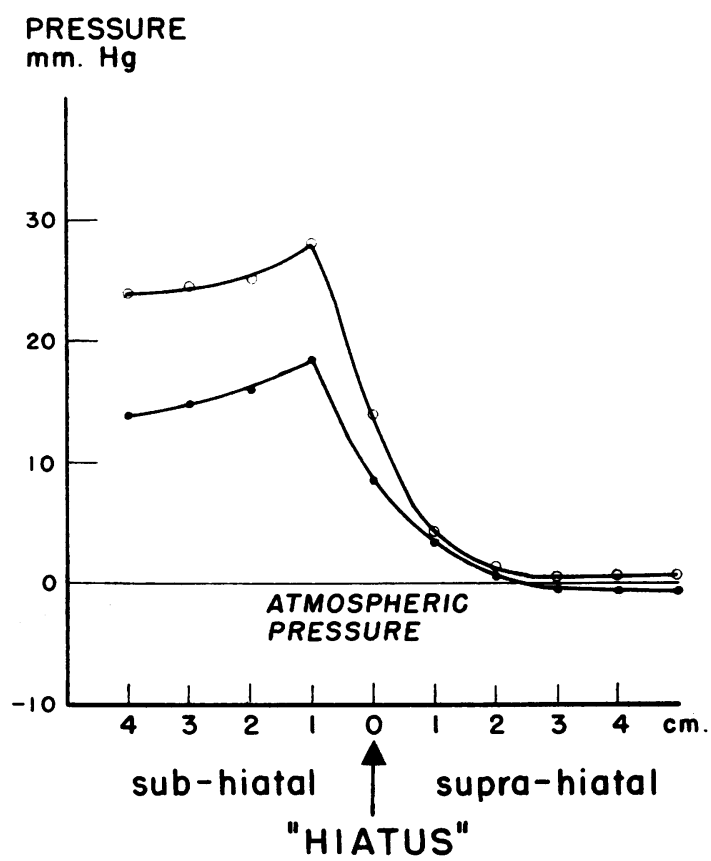

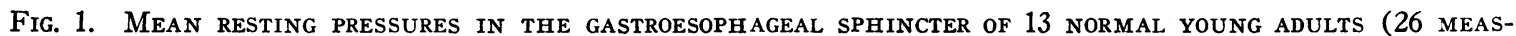
UREMENTS) DURING THE CONTROL PERIOD ( $\odot$ ) AND DURING EXTERNAL ABDOMINAL PRESSURE (O) WITH A FUNDIC PRESSURE RISE OF 10 MM HG.

end-inspiration. At end-expiration, the peak was present below the diaphragm in $40 \%$ of the observations, as compared to an incidence of $10 \%$ during the control period. The mean height of the high pressure zone did not change significantly (Table II, Figure 1).
The mean ratio between the amplitudes of 56 pressure increases in the subdiaphragmatic high pressure zone and in the fundus was 1 ; the mean ratio between the amplitude of 62 pressure increases in the supradiaphragmatic high pressure zone and in the fundus was 0.48 (Table III).

Mean ratio of the amplitudes of the pressure increases at the high pressure zone and in the fundus during increased intra-abdominal pressure

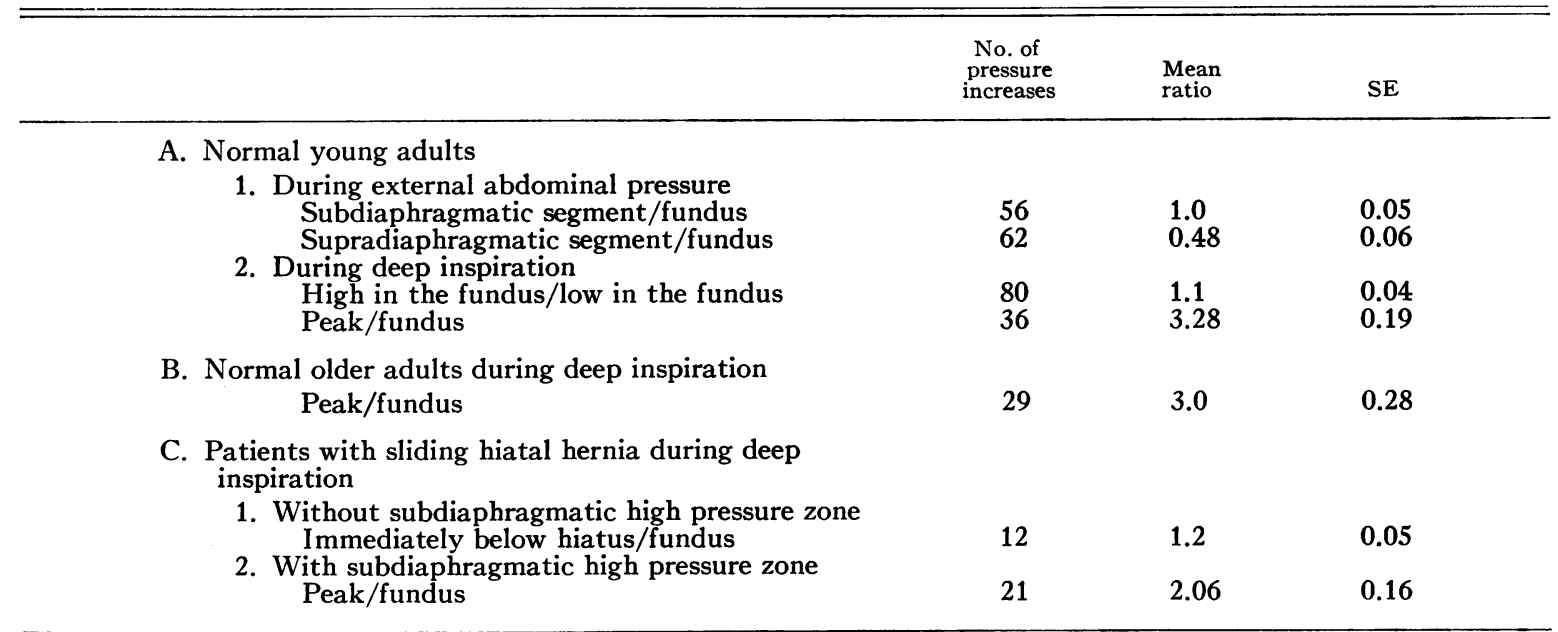



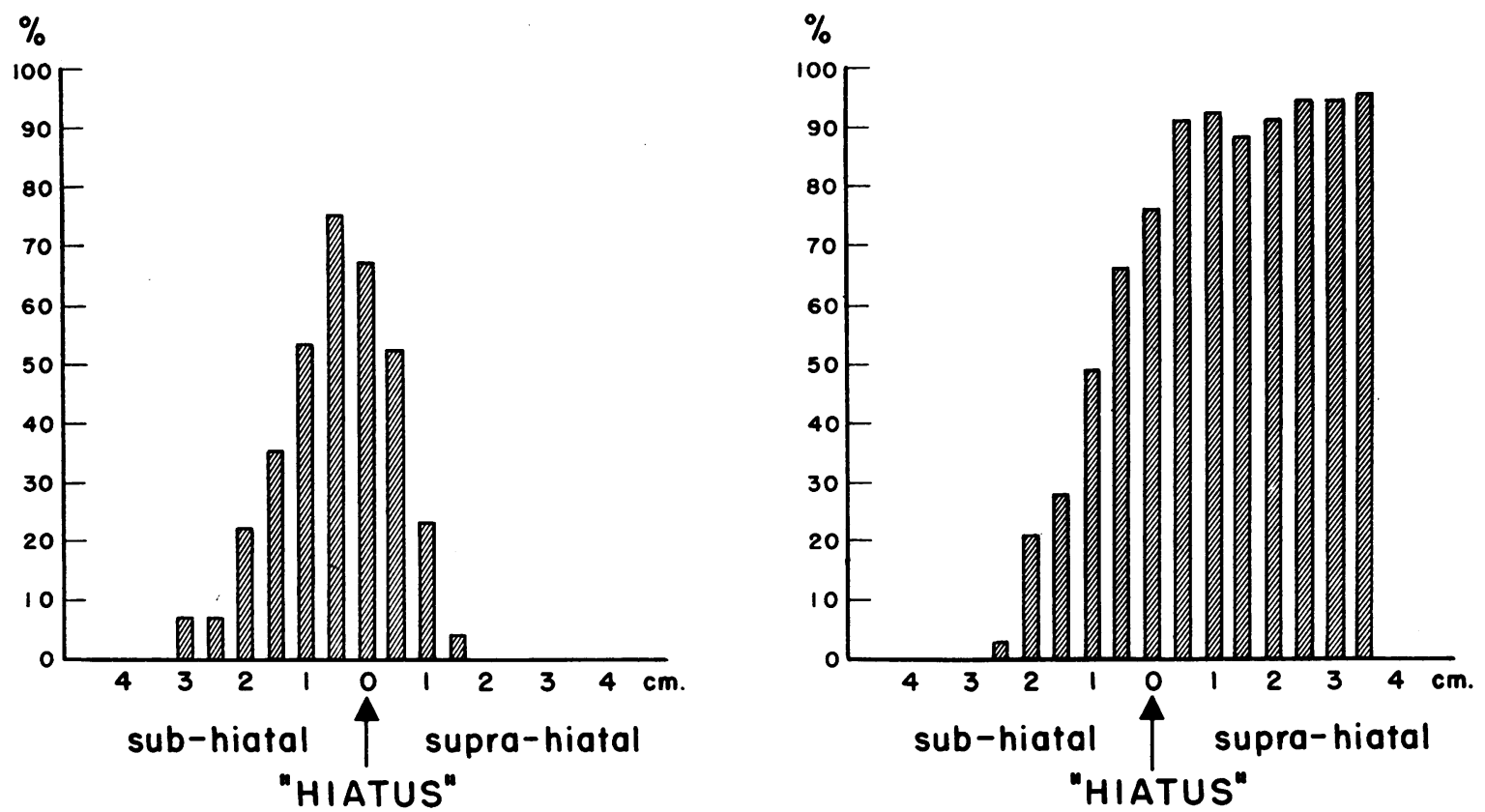

Fig. 2. INCIDENCE OF RELAXATIONS AND CONTRACTIONS AT DIFFERENT LEVELS OF THE GASTROESOPHAGEAL SPHINCTER OF 20 NORMAL YOUNG ADULTS (301 DEgLUtitions) DURING THE CONTROL PERIOD.

\section{RELAXATIONS}

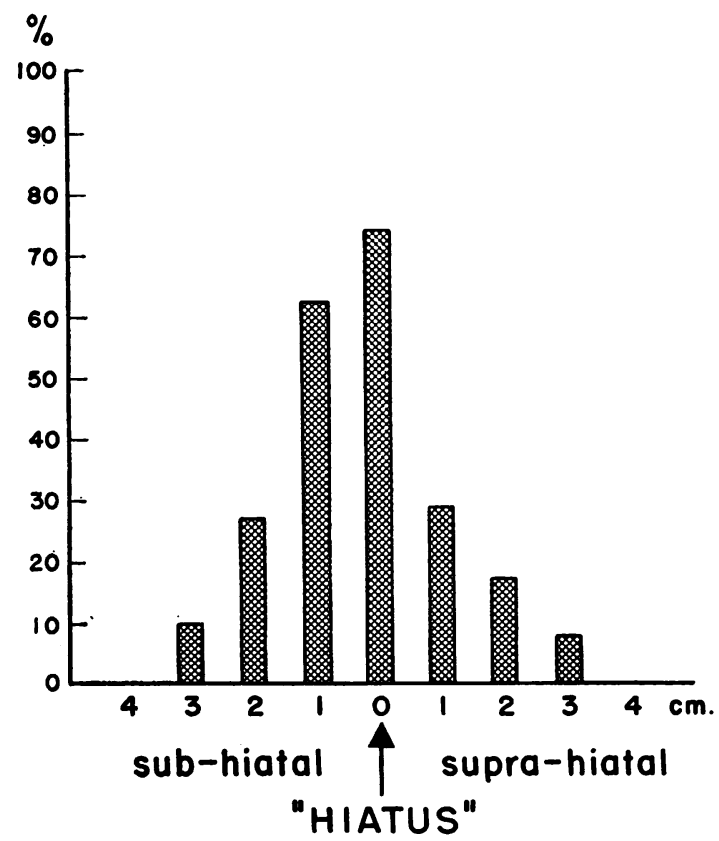

CONTRACTIONS

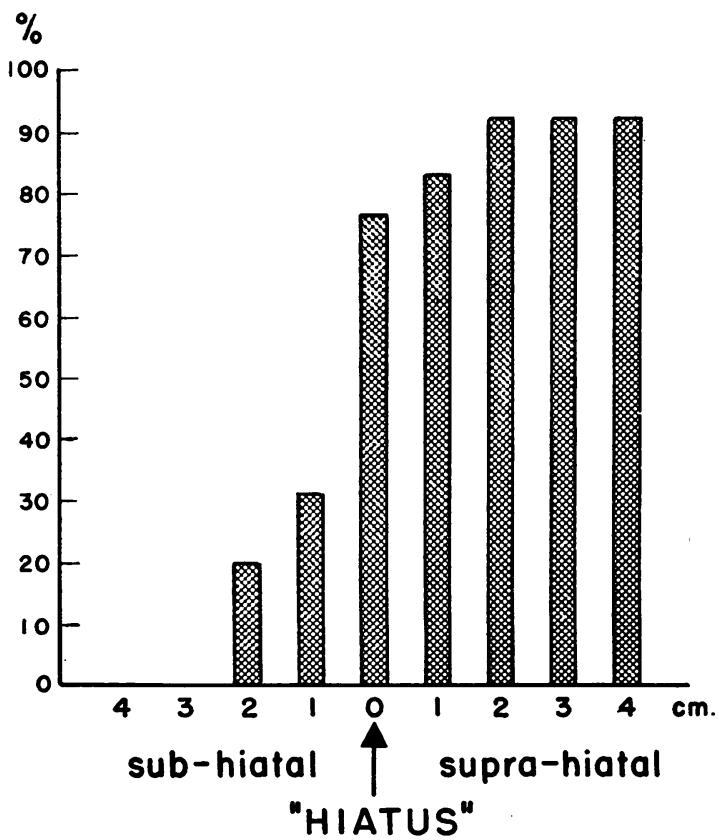

Fig. 3. INCIDENCE OF RELAXATIONS AND CONTRACTIONS AT THE DIFFERENT LEVELS OF THE GASTROESOPHAGEAL SPHINCTER of 19 NORMAL Young ADULTS (186 DEGLUTITIONS) DURING EXTERNAL ABDOMINAL PRESSURE. 
TABLE IV

Time of onset in relation to the beginning of deglutition and duration of relaxations and contractions

\begin{tabular}{|c|c|c|c|c|c|c|c|c|}
\hline & \multicolumn{4}{|c|}{ Relaxations } & \multicolumn{4}{|c|}{ Contractions } \\
\hline & \multicolumn{2}{|c|}{ Onset } & \multicolumn{2}{|c|}{ Duration } & \multicolumn{2}{|c|}{ Onset } & \multicolumn{2}{|c|}{ Duration } \\
\hline & Mean & $\mathrm{SE}$ & Mean & $\mathrm{SE}$ & Mean & $\mathrm{SE}$ & Mean & $\mathrm{SE}$ \\
\hline & \multicolumn{4}{|c|}{ seconds } & \multicolumn{4}{|c|}{ seconds } \\
\hline Before external abdominal pressure & & & & & & & & \\
\hline $\begin{array}{l}\text { a) Subdiaphragmatic segment } \\
\text { b) Supradiaphragmatic segment }\end{array}$ & $\begin{array}{l}1.2 \\
1.2\end{array}$ & $\begin{array}{l}0.2 \\
0.1\end{array}$ & $\begin{array}{l}7.5 \\
6.2\end{array}$ & $\begin{array}{l}0.3 \\
0.3\end{array}$ & $\begin{array}{l}9.3 \\
7.7\end{array}$ & $\begin{array}{l}0.4 \\
0.2\end{array}$ & $\begin{array}{r}10.7 \\
8.3\end{array}$ & $\begin{array}{l}0.6 \\
0.4\end{array}$ \\
\hline \multicolumn{9}{|l|}{ During external abdominal pressure } \\
\hline $\begin{array}{l}\text { a) Subdiaphragmatic segment } \\
\text { b) Supradiaphragmatic segment }\end{array}$ & $\begin{array}{l}1.2 \\
1.2\end{array}$ & $\begin{array}{l}0.2 \\
0.1\end{array}$ & $\begin{array}{l}9.2 \\
7.3\end{array}$ & $\begin{array}{l}0.7 \\
0.5\end{array}$ & $\begin{array}{l}9.9 \\
8.0\end{array}$ & $\begin{array}{l}0.6 \\
0.3\end{array}$ & $\begin{array}{l}13.4 \\
11.6\end{array}$ & $\begin{array}{l}2.3 \\
0.6\end{array}$ \\
\hline
\end{tabular}

Intraluminal pressure in the tubular esophagus proximal to the gastroesophageal sphincter did not change during abdominal compression.

During deglutition relaxation of the physiologic sphincter is normally followed by a contraction. Relaxations were detectable at the gastroesophageal junction in all subjects (38 high pressure zones). Of a total of 301 deglutitions, 106 (35\%) were accompanied by a demonstrable relaxation. The incidence of relaxations was highest just below the hiatus (Figure 2).

\section{END-EXPIRATION}

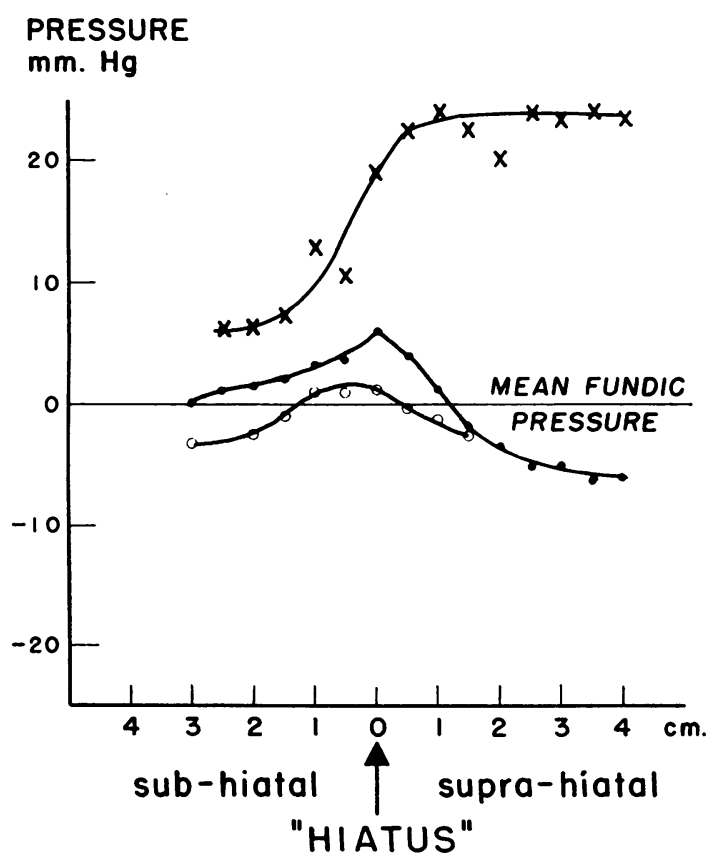

During abdominal compression, relaxations were demonstrable at the gastroesophageal junction in all but 2 subjects (29 high pressure zones). Of a total of 186 deglutitions, $68(36.5 \%)$ were accompanied by a demonstrable relaxation. The incidence of relaxations was highest at the hiatus (Figure 3).

Contractions at the gastroesophageal junction were found in all subjects (38 high pressure zones) during the control period. Of a total of 301 deglutitions, $184(61 \%)$ were followed by a

\section{END-INSPIRATION}

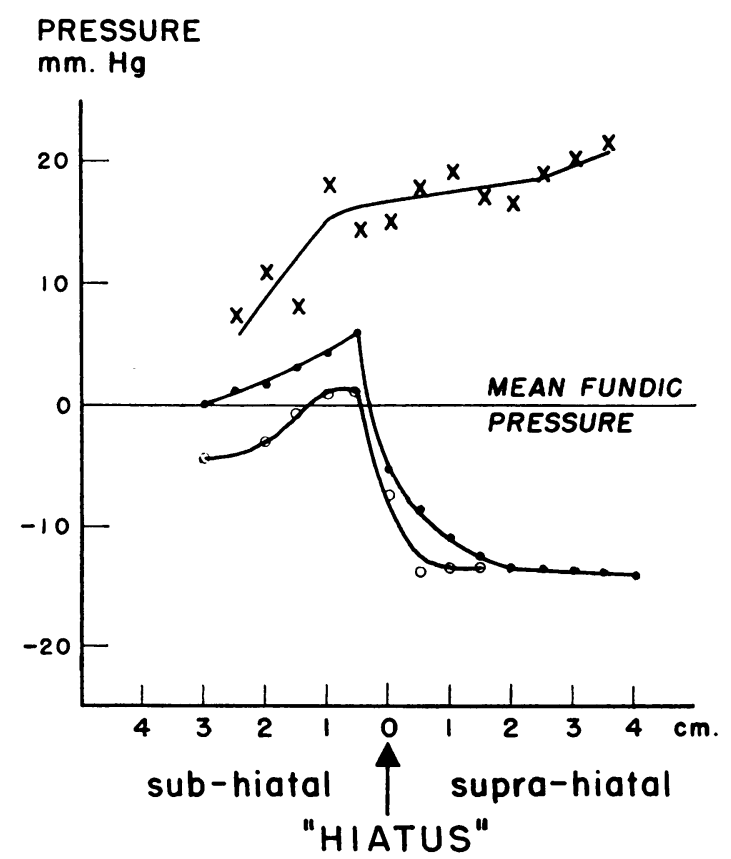

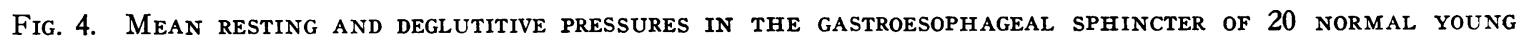
AdUlts (40 MEASUREMENTS) DURING THE CONTROL PERIOD. tractions; $O=$ mean amplitude of relaxations. 
END-EXPIRATION

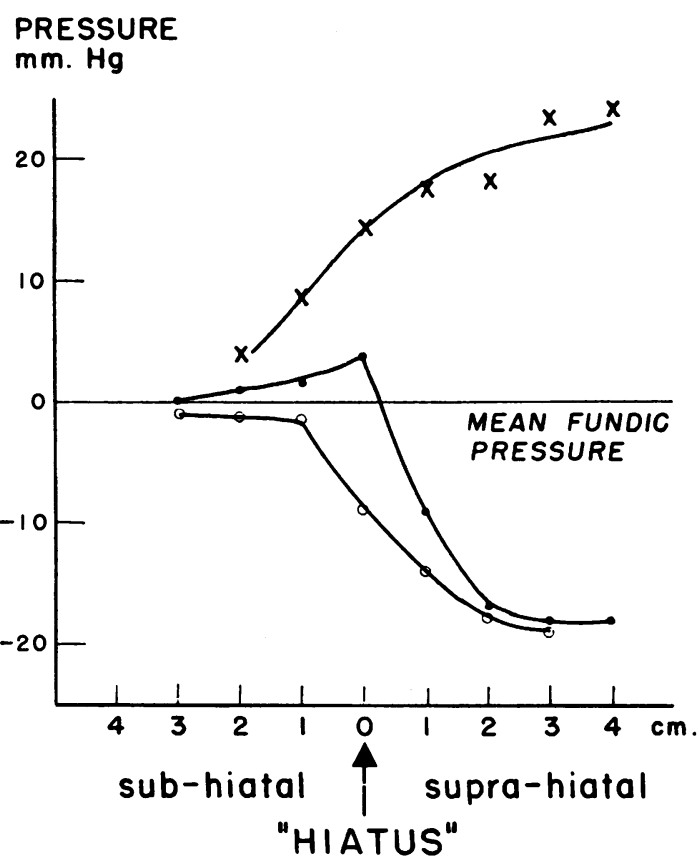

END-INSPIRATION

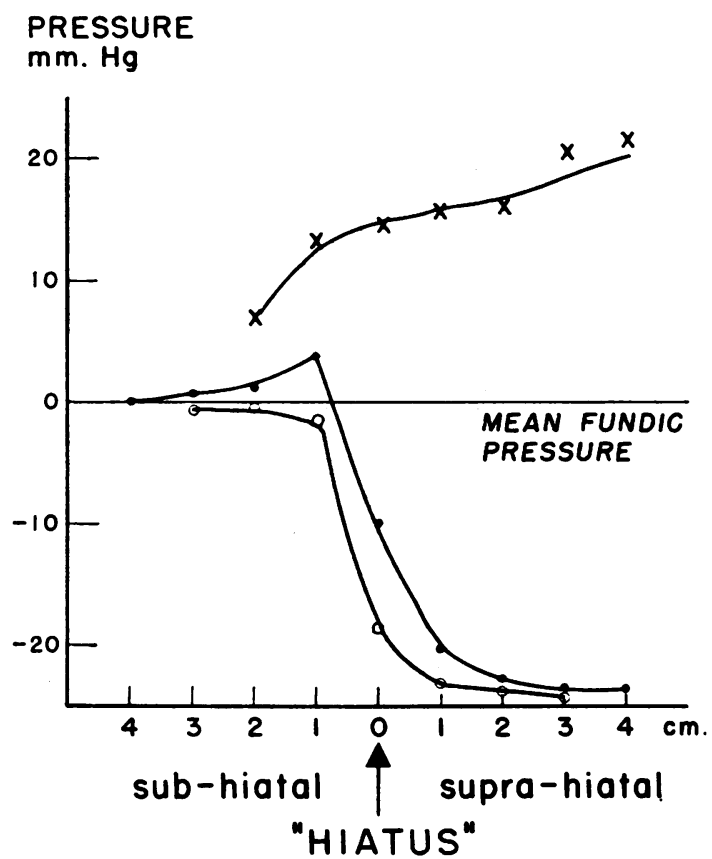

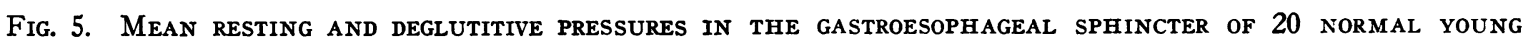
AdUlts (35 MEASUREMENTS) DURING eXternal ABDOMINal PRESSURE. $0=$ mean resting pressure; $\times=$ mean amplitude of contractions; $O=$ mean amplitude of relaxations.

contraction. The incidence of contractions was similar at all levels above the hiatus but decreased rapidly below the hiatus (Figure 2 ).

During abdominal compression, contractions at the gastroesophageal junction were found in 18 subjects ( 29 high pressure zones). Of a total of 186 deglutitions, $115(62 \%)$ were accompanied by contractions. The incidence of contractions was similar at all levels above the hiatus but decreased rapidly below the hiatus.
The time of onset of relaxations and contractions in relation to the onset of deglutition was similar for the entire high pressure zone during abdominal compression, but their duration increased significantly $(0.05>\mathrm{p}>0.01) \quad$ (Table IV).

During deglutition relaxations with pressures less than fundic pressure and contractions with pressure waves exceeding fundic pressure were demonstrated in all subjects during the control

TABLE V

Incidence of relaxations with pressures less than fundic pressure, and of contractions with pressures exceeding fundic pressure

\begin{tabular}{ccccc}
\hline \hline & \multicolumn{2}{c}{ Relaxations } & \multicolumn{2}{c}{ Contractions } \\
\cline { 2 - 6 } & $\begin{array}{c}\text { Subdia- } \\
\text { phrag- } \\
\text { matic } \\
\text { segment }\end{array}$ & $\begin{array}{c}\text { Supradia- } \\
\text { phrag- } \\
\text { matic } \\
\text { segment }\end{array}$ & $\begin{array}{c}\text { Subdia- } \\
\text { phrag- } \\
\text { matic } \\
\text { segment }\end{array}$ & $\begin{array}{c}\text { Supradia- } \\
\text { phrag- } \\
\text { matic } \\
\text { segment }\end{array}$ \\
\hline Before external abdominal pressure & & & & \\
a) End-expiration & 42 & 36 & 100 & 100 \\
b) End-inspiration & 40 & 100 & 100 & 100 \\
During external abdominal pressure & & 100 & 100 & 92 \\
a) End-expiration & 50 & 100 & 100 & 66 \\
b) End-inspiration & 48 & 100 & \\
\hline
\end{tabular}




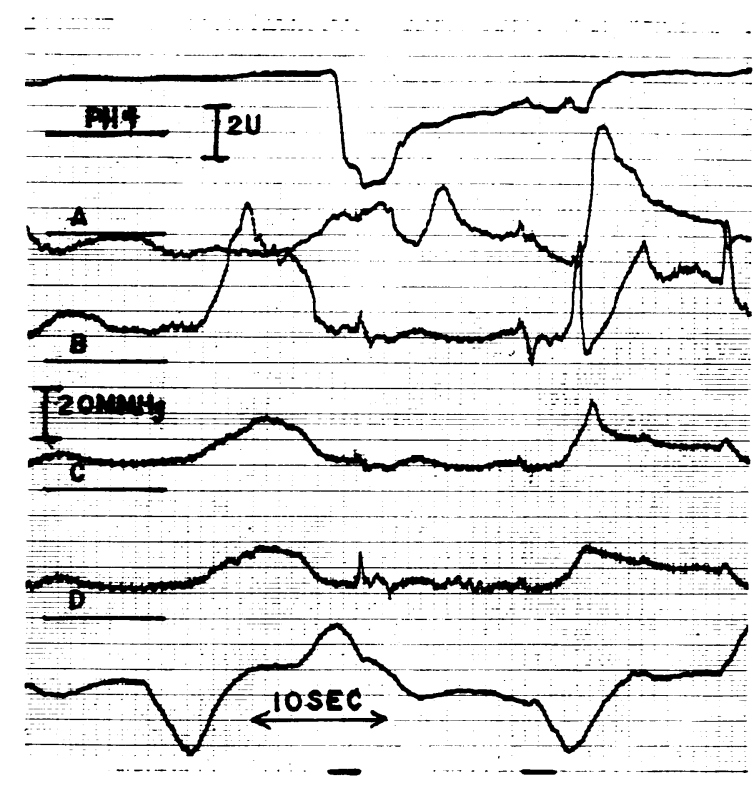

Fig. 6. Simultaneous intraluminal PH AND PRESSURE MEASUREMENTS DURING THE RESTING STATE, DEGLUTITION, AND DEEP INSPIRATION. The upper tracing represents the $\mathrm{pH}$ at $1 \mathrm{~cm}$ above the hiatus. The upper horizontal bar corresponds to the level of $\mathrm{pH} \mathrm{4}$, and the sensitivity is $2 \mathrm{U}$ per $\mathrm{cm}$. The 4 middle tracings represent the pressures at $3.5 \mathrm{~cm}$ above the hiatus, and $1.5 \mathrm{~cm}$, $3 \mathrm{~cm}$, and $8 \mathrm{~cm}$ below the hiatus. The horizontal bars $\mathrm{A}, \mathrm{B}, \mathrm{C}$, and D are the zero atmospheric pressures of the corresponding pressure tracings; the sensitivity is $2 \mathrm{~mm}$ $\mathrm{Hg}$ per $\mathrm{mm}$. Recording speed is $2.5 \mathrm{~mm}$ per second. The lower tracing records the respiratory movements, and the small bars at the bottom mark the onset of deglutition.

During the first deep inspiration catheter $B$ is at the subdiaphragmatic high pressure zone, and the amplitude of the pressure wave is 2.9 times higher than the amplitude of the corresponding fundic pressure waves (C and D). Also the peak comes 1 second earlier. During the second deep inspiration catheter $B$ is at the hiatus, and the biphasic wave is recorded immediately after the onset of deglutition. The amplitude of the peak is 2.4 times higher than the amplitude of the corresponding fundic pressure wave (D). Catheter $C$ is in the distal portion of the subdiaphragmatic high pressure zone, and the peak comes 0.2 second after the peak of the fundic pressure wave.

A fall of the $\mathrm{pH}$ of $4.4 \mathrm{U}$ occurs immediately after the onset of the first deglutition.

period. Immediately below and at the hiatus, a small zone was present where mean intraluminal pressure did not fall below fundic pressure during both phases of respiration (Figure 4).

The response after deglutition during external abdominal compression differed from that of the control period in that the zone where mean pressure exceeded fundic pressure was not present (Figure 5). This difference was accounted for by the increased incidence of relaxations during which the pressure in the physiologic sphincter fell below fundic pressure. The incidence of contractions during which intraluminal pressure exceeded fundic pressure decreased in the supradiaphragmatic segment of the sphincter during external abdominal pressure (Table V).

Gastroesophageal reflux was not observed during quiet respiration either during the control period or when intra-abdominal pressure was increased. A fall in $\mathrm{pH}$ of 1 to $4 \mathrm{U}$ was noted in the terminal $3 \mathrm{~cm}$ of the esophagus coincident with relaxation in $8(7.5 \%)$ of 107 deglutitions during the control period. Intraesophageal $\mathrm{pH}$ returned to predeglutition values in 6 of the 8 deglutitions $(75 \%)$ within 3 to 10 seconds (Figure 6).

A fall in $\mathrm{pH}$ of 1.5 to $3 \mathrm{U}$ was noted during 49 deglutitions $(39 \%)$ in 17 subjects during increased intra-abdominal pressure. Intraesophageal $\mathrm{pH}$ returned to predeglutition values in 19 deglutitions ( $40 \%$ ) within 3 to 34 seconds with the arrival of the peristaltic wave (Figure 7 ). The intraesophageal $\mathrm{pH}$ accompanying the other 30 deglutitions remained in the acidic range during the period of increased abdominal pressure.

The frequency of reflux during deglutition could not be correlated with the height of the fundic pressure increase in each individual. A sudden pressure rise in the lower third of the esophagus to the level of fundic pressure accompanied by inspiratory positive respiratory pressure waves was noted in $14 \%$ of the deglutitions during the period of increased abdominal pressure. Two subjects vomited.

3) Response of the physiologic sphincter to increased intra-abdominal pressure produced by deep inspiration

A) Normal subjects. The resting pressures at the gastroesophageal junction were measured 36 times during deep inspiration in 20 normal young adults (mean age, 23 years; range, 22 to 27 ) and 29 times in 22 normal older adults (mean age, 48; range, 35 to 74 ). The duration of deep inspiration varied between 2 and 24 seconds. The increase in fundic pressure was taken as an index 
of the depth of inspiration. The mean value was $15 \mathrm{~mm} \mathrm{Hg}$ (range, 4 to 36 ). Intraluminal pressures in the tubular esophagus decreased to the same degree concurrently.

The diaphragmatic hiatus was $1.5 \mathrm{~cm}$ (range, 1 to 4) more caudad during deep inspiration than during quiet respiration. The extent of this movement was not related to the depth of inspiration, as measured by an increase in fundic pressure, or to a decrease in intraesophageal pressure. A biphasic wave was recorded at the hiatus 29 times in 18 subjects. Pressures rose before or synchronous with the increase in fundic pressure. The duration of the positive wave depended upon the position of the recording tip with regard to the hiatus. The tip was so close to the hiatus on 2 occasions that the positive deflection lasted only 0.5 second and did not exceed fundic pressure.
Six times the high pressure zone during deep inspiration was at least $1.5 \mathrm{~cm}$ in length; measurements could therefore be made simultaneously from 2 levels of the high pressure zone $1.5 \mathrm{~cm}$ apart.

A biphasic wave was not recorded on 9 occasions. Pressure waves changed from inspiratory positive to inspiratory negative on withdrawal of the catheter $0.5 \mathrm{~cm}$.

A high pressure zone was always present but only below the hiatus. Its length was $1 \mathrm{~cm}$ (range, 0.5 to 3.5 ) shorter than during quiet respiration (Figure 8). The transition from fundic pressure to the pressure at the high pressure zone and from the latter to intraesophageal pressure was abrupt. The mean peak height of the high pressure zone was $28 \mathrm{~mm} \mathrm{Hg}$ (range, 8 to 60 ). This height had no uniform linear relation to the

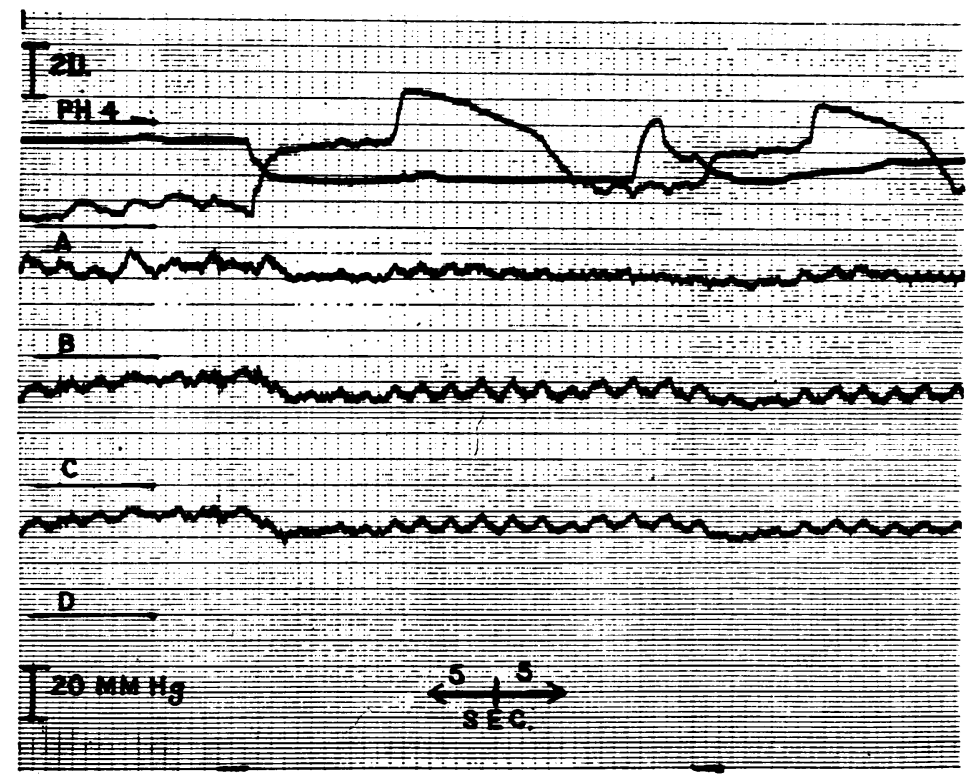

Fig. 7. Simultaneous intraluminal pH and PRESSURe measureMENTS DURING EXTERNAL ABDOMINAL PRESSURE WITH AN INCREASE OF FUNDIC PRESSURE OF $20 \mathrm{MM}$ Hg. The upper tracing represents the $\mathrm{pH}$ at $1.5 \mathrm{~cm}$ above the hiatus. The upper horizontal bar corresponds to the level of $\mathrm{pH} 4$; the sensitivity is $2 \mathrm{U}$ per $\mathrm{cm}$. The 4 lower tracings represent the pressures at $4 \mathrm{~cm}$ above the hiatus, $1 \mathrm{~cm}, 2.5 \mathrm{~cm}$, and 7.5 $\mathrm{cm}$ below the hiatus. The horizontal bars $\mathrm{A}, \mathrm{B}, \mathrm{C}, \mathrm{D}$ are the zero atmospheric pressures of the corresponding pressure tracings, and the sensitivity is $2 \mathrm{~mm} \mathrm{Hg}$ per $\mathrm{mm}$. Recording speed is $2.5 \mathrm{~mm}$ per second. The small bars at the bottom mark the onset of deglutition.

A fall of the $\mathrm{pH}$ of $1.6 \mathrm{U}$ occurs after the onset of deglutition. At the same time esophageal pressure rises to fundic pressure levels, and the respiratory waves become inspiratory positive. The pressure rise is followed by a contraction wave. 

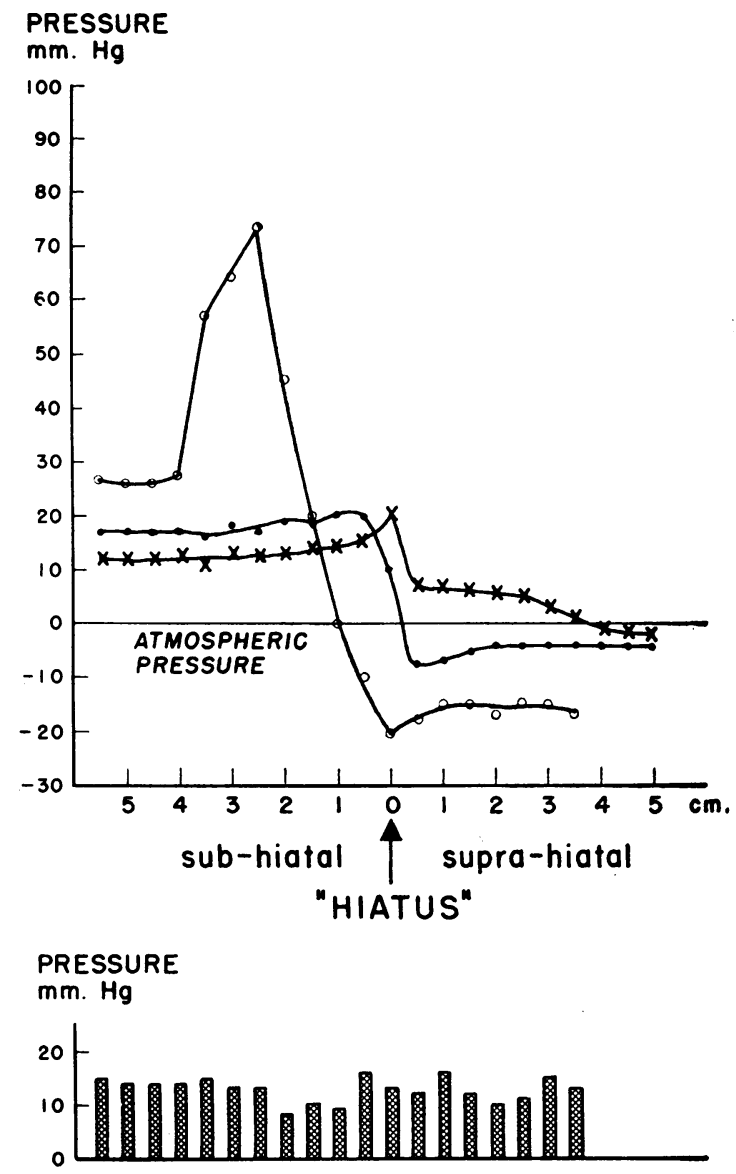

Fig. 8. MEAN RESTING PRESSURES IN THE GastroESOPHAGEAL SPHINCTER OF A YOUNG NORMAL ADULT DURING END-EXPIRATION $(X)$, END-INSPIRATION (O), AND DEEP INSPIRATION (O). The lower part of the Figure shows the amplitudes of the simultaneously recorded fundic pressure waves during deep inspiration. Pressure at the peak of the deep-inspiratory high pressure zone is 4.7 times higher than the amplitude of the fundic pressure wave.

amplitude of the fundic or esophageal pressure waves.

The mean gastroesophageal pressure gradient was $32 \mathrm{~mm} \mathrm{Hg}$ (range, 22 to 46) at the height of inspiration. During deep inspiration a mean fundic pressure increase of $12 \mathrm{~mm} \mathrm{Hg}$ was obtained. The mean ratio of maximal pressure of the high pressure zone/fundic pressure produced by deep inspiration was 3.28 for the young adults and 3.0 for the older adults (Table III). The ratio was independent of the amplitude of the fundic pressure waves.

The intraluminal pressure measurements were repeated 10 minutes after intravenous injection of $30 \mathrm{mg}$ of propantheline in 6 subjects. During deep inspiration the ratio between the amplitudes of the pressure waves at the peak of the high pressure zone and in the fundus was not influenced by propantheline, but the height of the high pressure zone decreased significantly during quiet respiration (Table VI).

Further analysis of the individual pressure waves at the high pressure zone and in the gastric fundus during deep inspiration suggested that mechanisms other than increased intra-abdominal pressure might be at work. A biphasic respiratory wave is normally recorded at the hiatus. However, the rate of pressure rise of the positive component was greater than the similar rate of the simultaneous waves in the abdominal high pressure zone, where identical pressures were reached 0.4 to 0.8 second later; the rate was even greater than the rate of the simultaneous fundic waves (Figure 9). The dip of the negative component at the hiatus occurred simultaneously with the peak of the fundic pressure wave. When the respiratory pressure waves at the mid- and distal portions of the high pressure zone were compared with those occurring simultaneously in the fundus, the following were noted: the peak of the pressure waves during deep inspiration occurred before in $57 \%$, synchronous with in $38 \%$, or after the peak of the fundic pressure waves in $4.5 \%$ of the observations at the mid-portion of the high pressure zone; the corresponding values at the distal end of the high pressure zone were $13 \%, 50 \%$, and $73 \%$. The difference in time ranged from 3 seconds before to 2 seconds after the peak of the fundic pressure waves. The duration of $50 \%$

TABLE VI

Influence of propantheline on the height of the high pressure zone during quiet respiration, and on the ratio between the amplitudes of the pressure waves at the peak of the high pressure zone and in the fundus during deep inspiration

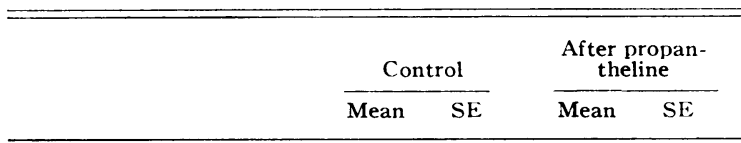

Quiet respiration, $\mathrm{mm} \mathrm{Hg}$

$\begin{array}{lllll}\text { a) End-expiration } & 8.7 & 1.5 & 1.1 & 0.4 \\ \text { b) End-inspiration } & 5.7 & 0.8 & 2.0 & 0.5 \\ \text { Deep inspiration } & 2.5 & 0.2 & 2.8 & 0.3\end{array}$


of the pressure waves was 10 to $40 \%$ shorter at the high pressure zone than the duration of the corresponding fundic pressure waves; this incidence increased to $80 \%$ for deep inspirations longer than 10 seconds.

The $\mathrm{pH}$ frequently increased in the entire high pressure zone during deep inspiration, reaching values similar to those recorded 0.5 to $2.5 \mathrm{~cm}$ more proximal during quiet respiration.

$B$ ) Patients with sliding hiatal hernia. Eighteen patients (mean age, 56 years; range, 41 to 72 ) with a sliding hiatal hernia were studied. An infradiaphragmatic high pressure zone was not present, either during quiet respiration or deep inspiration, in six patients, whose hernias had a mean length of $5 \mathrm{~cm}$ (range, 2 to 12). The mean ratio between the amplitudes of the pressure waves immediately below the hiatus and $5 \mathrm{~cm}$ lower in the fundus produced by deep inspiration was 1.2 (Table III). This value was not significantly different from 1.1, the mean ratio between amplitudes of the pressure waves produced by deep inspiration in the fundus at a $5-\mathrm{cm}$ interval in normal subjects.

A subdiaphragmatic high pressure zone was present at the time of the study in 12 patients with smaller hernias (mean length, $3.5 \mathrm{~cm}$; range, 2 to 5 ) during quiet respiration and deep inspiration. The mean maximal pressure of the high pressure zone during quiet respiration was not significantly different from that of the normal subjects, being $6 \mathrm{~mm} \mathrm{Hg}$ (SE, 0.81) at end-expiration and $4.1 \mathrm{~mm} \mathrm{Hg}(\mathrm{SE}, 0.54)$ at end-inspiration. During deep inspiration the mean length of the high pressure zone was $1 \mathrm{~cm}$ less than during quiet respiration. The mean ratio between the amplitudes of the pressure waves produced by deep inspiration at the peak of the high pressure zone and in the fundus was 2.06 (Table III). This ratio was significantly smaller than the corresponding ratio in normal subjects of either age group $(0.01>p>0.005)$.

The pressure waves produced by deep inspiration at the high pressure zone were 10 to $45 \%$ shorter than the duration of the corresponding fundic pressure waves in $70 \%$ of the observations. The incidence increased to $80 \%$ for waves produced by deep inspiration of longer than 10 seconds duration.

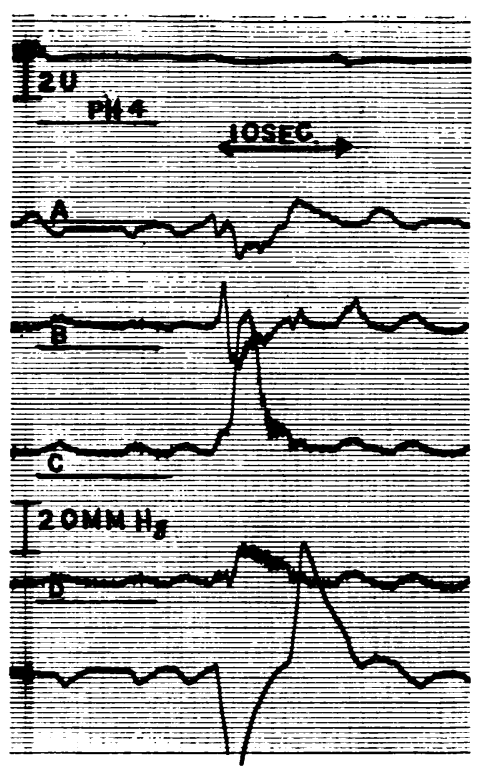

Fig. 9. Simultaneous intraluminal pH and PresSURE MEASUREMENTS DURING QUIET RESPIRATION AND DEEP INSPIRATION. The upper tracing represents the $\mathrm{pH}$ at $1 \mathrm{~cm}$ above the hiatus. The upper horizontal bar corresponds to the level of $\mathrm{pH} \mathrm{4}$, and the sensitivity is 2 $U$ per $\mathrm{cm}$. The 4 middle tracings represent the pressures at $3.5 \mathrm{~cm}$ above the hiatus, and $1.5 \mathrm{~cm}, 3 \mathrm{~cm}$, and $8 \mathrm{~cm}$ below the hiatus. The horizontal bars A, B, C, D are the zero atmospheric pressures of the corresponding pressure tracings, and the sensitivity is $2 \mathrm{~mm} \mathrm{Hg}$ per $\mathrm{mm}$. Recording speed is $2.5 \mathrm{~mm}$ per second. The lower tracing records the respiratory movements.

During deep inspiration catheter $B$ is at the hiatus; catheter $\mathrm{C}$ at the distal portion of the high pressure zone. The positive peak of the biphasic wave in $B$ comes 0.8 second before the time at which the same pressure is reached in $\mathrm{C}$. The peak of the deep inspiratory pressure wave in $C$ comes 0.2 second after the peak of the fundic pressure wave in $D$.

\section{Discussion}

Although the isolated gastroesophageal sphincter possesses intrinsic tone and activity, the mechanisms that maintain sphincter tone and permit relaxation are still controversial (11). The pressures in the high pressure zone result not only from esophageal muscle tone but reflect extraesophageal respiratory pressure variations within the thorax and abdomen.

External abdominal compression and deep inspiration resulted in different responses to a comparable increase in intra-abdominal pressure. During external abdominal pressure the mean fundic pressure rise was $14 \mathrm{~mm} \mathrm{Hg}$, and the mean 
increase in the gastroesophageal pressure gradient was $20 \mathrm{~mm} \mathrm{Hg}$ at end-expiration and $27 \mathrm{~mm}$ $\mathrm{Hg}$ at end-inspiration. Similar fundic pressure rises occur as the result of changes in posture (1). The characteristics of infradiaphragmatic segment of the high pressure zone were the same as during quiet respiration.

During deglutition relaxations of the sphincter were of longer duration during the period of increased abdominal pressure as compared to quiet respiration. At and below the hiatus a small zone was found during quiet respiration where the mean pressures during relaxation of the sphincter were higher than fundic pressure. This small band has been postulated to be guardian pressure against regurgitation at the moment when the resting barrier has disappeared (12). During abdominal compression, the number of relaxations during which pressure in the sphincter fell below fundic pressure increased, resulting in the temporary disappearance of the small pressure barrier between the fundus of the stomach and the tubular esophagus.

The changes in intraluminal $\mathrm{pH}$ were in accord with the changes in intraluminal pressure. The occurrence of reflux in normal subjects only at the moment of relaxation emphasizes the importance of the physiologic sphincter, and particularly its infradiaphragmatic segment, in the prevention of reflux.

During deep inspiration, the mean rise in fundic pressure was $12 \mathrm{~mm} \mathrm{Hg}$, comparable to that which occurred during abdominal compression. In contrast, the mean gastroesophageal gradient during deep inspiration increased to $32 \mathrm{~mm} \mathrm{Hg}$, almost three times the increase in fundic pressure.

The characteristics of the high pressure zone during deep inspiration were different from those of the high pressure zone during resting respiration. During deep inspiration the band of high pressure was sharply delineated and restricted to the abdominal esophagus. The characteristics of the pressure waves at the high pressure zone differed from the characteristics of the pressure waves in the fundus. Although Wolf and Cohen (13) have attributed this phenomenon to the special hydrodynamic features of this area, two other mechanisms can be postulated for the production of the high pressure zone during deep inspiration, namely, a rise in tone of the muscular wall of the gastroesophageal junction or external compression by the crura of the diaphragm. High resting pressures have been recorded in the gastroesophageal sphincter (14). A sharp rise in muscular tone restricted to a small portion of the abdominal segment of the sphincter and produced only by deep inspiration is, however, not likely. The tone of the gastroesophageal sphincter is reduced by anticholinergic drugs $(15,16)$. Deep inspiration was accompanied by a narrow band of high pressure at the moment of relaxation of the sphincter and when sphincteric tone had been reduced by parenteral administration of propantheline.

Monges (17) related pressure changes at the hiatus during deep inspiration to a crural action. Compression by the crura could produce the narrow band of high pressure independent of esophageal tone and the increase in intra-abdominal pressure. The peripheral portion of the diaphragm does not necessarily act in concert with the central portion, which is mainly responsible for the rise in intra-abdominal pressure during deep inspiration (18). The present findings agree, as the ratios between the amplitudes of the inspiratory pressure waves at the high pressure zone and in the fundus were not related to the increase in intra-abdominal pressure. Rather, the occurrence of the peak of the pressure waves at the high pressure zone before, synchronous with, or after the peak of the fundic pressure wave, at the hiatus, middle and distal portions of the high pressure zone, respectively, is consistent with a downward movement of the crura over the physiologic sphincter.

In patients with sliding hiatal hernia the hiatal ring is widened, and displacement of the high pressure zone into the thorax has been observed $(7,19)$. The high pressure zone may be in normal position at the time of manometric study; a concomitant reduction of the hernia must be assumed. In 6 patients with sliding hiatal hernia who had complete absence of the high pressure zone below the diaphragm during resting respiration, no high pressure zone was detected during deep inspiration. In 12 patients who had small sliding hiatal hernias, a high pressure zone was found below the hiatus during quiet respiration, mainly during end-inspiration. During deep inspiration a high pressure zone was present in all 
patients and was qualitatively similar to the high pressure zone of normal subjects during deep inspiration. However, the mean maximal pressure of the high pressure zone was significantly less during deep inspiration, being only twice that of the increase in fundic pressure. The inspiratory pressure waves were more often of shorter duration at the high pressure zone than in the fundic region. A less forceful compression of shorter duration by the distended hiatal ring could account for these findings.

The importance of crural compression in the prevention of reflux during deep inspiration remains to be determined. No reflux occurs during deep inspiration with or without simultaneous deglutition. The barrier during deep inspiration may be a useful support of the gastroesophageal sphincter at the moment of an increased gastroesophageal pressure gradient.

\section{Summary}

1. Simultaneous intraluminal pressures and $\mathrm{pH}$ in the area of the physiologic gastroesophageal sphincter were recorded in 42 normal subjects and 18 patients with sliding hiatal hernia.

2. The presence of a high pressure zone corresponding to the physiologic gastroesophageal sphincter was confirmed. At end-expiration the mean length of this zone extended from $2.5 \mathrm{~cm}$ (range, 0.5 to 3.0 ) below the hiatus to $1 \mathrm{~cm}$ (range, 0.5 to 2.5 ) above the hiatus. The mean height of the peak was $6 \mathrm{~mm} \mathrm{Hg}$ (range, 1 to 17) at end-expiration.

At end-inspiration the mean length of this zone extended from $2.5 \mathrm{~cm}$ (range, 0.5 to 3.5 ) below the hiatus to $0.75 \mathrm{~cm}$ (range, 0 to 1 ) above the hiatus. The mean height of the peak was $4 \mathrm{~mm}$ $\mathrm{Hg}$ (range, 1 to 12 ).

3. The influence of external abdominal compression and of deep inspiration on function of the physiologic gastroesophageal sphincter and the occurrence of reflux was investigated.

4. Increased intra-abdominal pressure from external abdominal compression did not alter the gradient between the subhiatal sphincter and the fundus.

5. Evidence of reflux was present only during deglutition. The incidence of reflux increased significantly when intra-abdominal pressure was elevated concurrently.
6. During deep inspiration the pressure changes in the physiologic gastroesophageal sphincter were compatible with a superimposed pinchcock action of the diaphragm. The latter changes were not related to the depth of inspiration, and a diaphragmatic action during quiet respiration could not be excluded.

7. A similar response was observed in some patients with sliding hiatal hernias, but to a significantly lesser degree and only when a subdiaphragmatic high pressure zone was present during quiet respiration.

\section{Acknowledgments}

It is a pleasure to acknowledge the assistance of Miss Sylvia Klevans. Drs. F. J. Ingelfinger, C. F. Code, and $B$. R. Cohen reviewed the manuscript and made valuable suggestions.

\section{References}

1. Fyke, F. E., Jr., C. F. Code, and J. F. Schlegel. The gastroesophageal sphincter in healthy human beings. Gastroenterologia (Basel) 1956, 86, 135

2. Creamer, B., C. K. Harrison, and J. W. Pierce. Further observations on the gastro-œsophageal junction. Thorax 1959, 14, 132.

3. Vantrappan, G., E. C. Texter, Jr., C. J. Barborka, and $\mathrm{J}$. Vandenbroucke. The closing mechanism at the gastroesophageal junction. Amer. J. Med. 1960, 28, 564.

4. Wolf, B. S. The esophagogastric closing mechanism: role of the abdominal esophagus. J. Mt Sinai Hosp. 1960, 27, 404.

5. Nagler, R., and H. M. Spiro. Segmental response of the inferior esophageal sphincter to elevated intragastric pressure. Gastroenterology 1961, 40, 405.

6. Cohen, B. R., and B. S. Wolf. Roentgen localization of the physiologically determined esophageal hiatus. Gastroenterology 1962, 43, 43.

7. Texter, E. C., Jr., G. Van Derstappen, G. Chejfec, V. E. Chvojka, M. Vidinli, C. J. Barborka, and W. E. Bundesen. Criteria for the diagnosis of hiatal hernia. Arch. intern. Med. 1962, 110, 827.

8. Maclaurin, $C$. The intrinsic sphincter in the prevention of gastro-œsophageal reflux. Lancet 1963, 2, 801 .

9. Monges, $\mathrm{H}$. Considérations sur le rôle du diaphragme dans la physiologie de la continence gastroœsophagienne et sur la projection radiologique de l'hiatus œsophagien. Gastroenterologia (Basel) 1956, 86, 232.

10. Rovelstad, R. A., C. A. Owen, Jr., and T. B. Magath. Factors influencing the continuous recordings of in situ $\mathrm{pH}$ of gastric and duodenal contents. Gastroenterology 1952, 20, 609. 
11. Mann, C. V., J. F. Schlegel, F. H. Ellis, Jr., and C. F. Code. Studies of the isolated gastroesophageal sphincter. Surg. Forum 1962, 13, 248.

12. Kelley, M. L., Jr., D. L. Wilbur III, J. F. Schlegel, and C. F. Code. Deglutitive responses in the gastroesophageal sphincter of healthy human beings. J. appl. Physiol. 1960, 15, 483.

13. Wolf, B. S., and B. R. Cohen. Radiographic localization of the esophageal hiatus as determined by intraluminal pressure measurements. Radiology 1961, 76, 903.

14. Code, C. F., J. F. Schlegel, M. L. Kelley, Jr., A. M. Olsen, and F. H. Ellis, Jr. Hypertensive gastroesophageal sphincter. Proc. Mayo Clin. 1960, 35, 391.
15. Ingelfinger, F. J. Esophageal motility. Physiol. Rev. 1958, 38, 533.

16. Bettarello, A., S. G. Tuttle, and M. I. Grossman. Effect of autonomic drugs on gastroesophageal reflux. Gastroenterology 1960, 39, 340.

17. Monges, $H$. Données anatomiques, radiologiques et physiologiques sur l'hiatus œsophagien. Bibl. gastroent. (Basel) 1960, 1, 3.

18. Joannides, M. Influence of the diaphragm on the esophagus and on the stomach. Arch. intern. Med. 1929, 44, 856.

19. Atkinson, M., D. A. W. Edwards, A. J. Honour, and E. N. Rowlands. The œesophagogastric sphincter in hiatus hernia. Lancet 1957, 2, 1138. 